\title{
Analisis Kualitas Plankton dan Benthos Tambak Bontang Kuala Kota Bontang Kalimantan Timur
}

\author{
Henny Pagoray ${ }^{1}$ dan Deni Udayana ${ }^{2}$ \\ 1,2 Program Studi Budidaya Perairan Jurusan Budidaya Periran \\ Fakultas Perikanan dan Ilmu Kelautan Universitas Mulawarman \\ $\mathrm{Jl}$. Gunung Tabur Kampus Gunung kelua \\ ${ }^{1}$ e-mail korenpondensi: pagoray.henny@gmail.com
}

\begin{abstract}
Water pond cultivation was greatly limited by the water fertility. Water fertility would affect the productivity of ponds. One of the factors that influence on the productivity of the pond was plankton and benthos. Plankton as a natural feed had a role in the feed chain that would produce growth and biota of cultivated life. Results of plankton quality analysis in ponds Welfare index (1.55-1.88) categorized as medium category, communities $(0.96-0.98)$ uniformity was stable and there were no dominant $(0.16$ 0.22) type in plankton dominance. Benthos rich site index was categorized as low (0.00-0.54); and there were found some dominant (0.73-1) type in benthos dominance. It could be concluded that the productivity of Bontang Kuala pond was categorized as medium category.
\end{abstract}

Keywords: Bontang Kuala, quality of benthos, plankton, pond

\begin{abstract}
ABSTRAK
Usaha budidaya tambak sangat dipengaruhi oleh kesuburan perairan. Kesuburan perairan akan mempengaruhi produktivitas tambak. Salah satu faktor yang berpengaruh terhadap produktivitas tambak yaitu plankton dan benthos. Plankton sebagai pakan alami mempunyai peran dalam rantai makanan yang akan berpengaruh terhadap pertumbuhan dan kelangsungan hidup biota yang dibudidayakan. Hasil analisis kualitas plankton pada tambak diketahui indeks keanekaragaman $(1,55-1,88)$ termasuk dalam kategori sedang, keseragaman $(0,96-0,98)$ kategori komunitas stabil dan dominansi $(0,16-0,22)$ tidak ada jenis yang mendominasi. Indeks keanekaragaman benthos termasuk kategori komunitas rendah $(0,00-0,54)$; sedangkan dominansi $(0,73-1)$ ada jenis benthos yang mendominasi. Dapat disimpulkan bahwa produktivitas tambak Bontang Kuala termasuk dalam kategori sedang.

Kata Kunci: Bontang Kuala, kualitas benthos, plankton, tambak
\end{abstract}

\section{Pendahuluan}

Usaha budidaya tambak sangat dipengaruhi oleh kesuburan perairan dan tanah tambak. Kesuburan perairan akan mempengaruhi produktivitas perairan tersebut. Produktivitas utama adalah kecepatan penimbunan energi (melalui proses fotosintesa) dari organisme-organisme produsen, jadi organisme produsen menentukan besar kecilnya produktivitas ekosistem tambak secara keseluruhan. Jika dalam suatu tambak organisme produsen menghasilkan bahan makanan bagi organisme lain (konsumen) maka tambak tersebut dikatakan subur.

Tambak yang subur sangat menguntungkan bagi organisme konsumen (ikan, udang dan lain-lain), karena organisme konsumen dapat hidup baik dan melakukan pertumbuhan secara maksimal. Pada tambak organisme pembusuk aktif menyediakan unsur-unsur hara untuk kebutuhan produsen. Demikian seterusnya sehingga energi selalu 
berputar dalam ekosistem tambak, yaitu dari lingkungan ke organisme dan dari organisme kembali ke lingkungan. Pada lingkungan yang stabil perputaran energi akan seimbang, tetapi apabila ada suatu masalah di sekitar lingkungan tersebut maka akan memberikan pengaruh terhadap lingkungan sekitarnya. Begitu juga dengan produktivitas tambak akan sangat dipengaruhi oleh kondisi sekitarnya (lingkungan).

Untuk mengetahui produktivas tambak tersebut maka perlu dilakukan suatu penelitian untuk mengidentifikasi kondisi tambak tersebut, dengan melihat faktor-faktor yang berpengaruh terhadap produktivitas tambak. Parameter, daya dukung lingkungan tambak yang berpengaruh adalah; kualitas air ditinjau dari segi fisik, kimia, biologi, dan tingkat kesuburan tanah berdasarkan kesediaan haranya (Musa, 2004).

Salah satu faktor yang berpengaruh terhadap produktivitas tambak yaitu pakan alami (plankton). Plankton merupakan organisme yang mengapung atau bergerak mengikuti arus. Plankton terdiri fitoplankton dan zooplankton dan keduanya mempunyai peran penting dalam ekosistem di perairan. Fitoplankton sebagai produktivitas primer, sehingga sangat penting pada rantai makanan (Nybakken, 1992). Produktifitas fitoplankton dipengaruhi oleh ketersediaan nitrogen dan fospor. Fitoplankton hanya bisa hidup di tempat yang mempunyai sinar yang cukup, hal ini berkaitan dengan proses fotosintesa, sehingga fitoplankton lebih banyak dijumpai pada daerah permukaan perairan, atau daerah-daerah yang kaya akan nutrien (Hutabarat dan Evans, 1995).

\section{Tujuan dan Manfaat Penelitian}

Tujuan penelitian adalah mengetahui kualitas plankton dan benthos dengan melihat jenis, keanekaragaman, keseragaman dan dominansi. Manfaat dari penelitian sebagai bahan informasi bagi petani tambak untuk melakukan pengelolaan tambak yang baik sehingga dapat memberikan hasil yang maksimal.

\section{Metodologi Penelitian Tempat dan Waktu Penelitian}

Penelitian dilakukan di areal pertambakan Bontang Kuala di Kota Bontang Kalimantan Timur. Penelitian dilakukan pada bulan Agustus 2017. Analisis kualitas plankton dan benthos di laboratorium Jurusan Budidaya Perairan Fakultas Perikanan dan IImu Kelautan Universitas Mulawarman Samarinda Kalimantan Timur.

\section{Alat dan Bahan}

Pada penelitian yang dilakukan di tambak Bontang Kuala, ada beberapa alat dan bahan yang digunakan seperti : Mikroskop, plankton net, botol sampel untuk plankton, cold box, ekmad grab, plastik dan formalin untuk pengawet. 


\section{Analisa sampel benthos dan plankton}

Sampel benthos diambil pada tiga (3) titik di tambak, yaitu pada in let, bagian tengah dan out let. Pengambilan sampel benthos dengan menggunakan alat yaitu ekmand grab. Sampel benthos di bawa ke laboratorium untuk dilakukam identifikasi. Sampel plankton juga dilakukan pengambilan sampel pada tiga (3) titik di tambak (sama dengan lokasi pengambilan sampel benthos). Pengambilan sampel plankton dengan menggunakan alat plankton net. Sampel air yang berisi plankton diberi bahan pengawet (formalin). Sampel di bawa ke laboratorium untuk dilakukan identifikasi. Identifikasi dilakukan menggunakan mikroskop. Buku Identifikasi yang digunakan yaitu menurut : Davis (1955), Newell and Newell (1963), dan Yamaji (1979).

\section{Analisa Data}

Keanekaragaman plankton (indeks keanekaragaman dihitung dengan menggunakan rumus:

$$
\mathrm{H}=-\sum_{\mathrm{i}=1}^{\mathrm{n}}\left[\left(\frac{\mathrm{ni}}{\mathrm{N}}\right)\right] \ln \left[\left(\frac{\mathrm{ni}}{\mathrm{N}}\right)\right]
$$

Sumber : Kendeigh (1980)

Keterangan:

$\mathrm{H}=$ Indeks diversitas (keanekaragaman)

ni $=$ jumlah individu setiap jenis

$\mathrm{N}=$ jumlah total individu

Keseragaman plankton (indeks keseragaman) denga menggunakan rumus :

$$
E=\frac{\mathrm{H}^{1}}{\mathrm{H} \mathrm{maks}}
$$

(2)

$$
\begin{aligned}
& \text { Keterangan : } \\
& E=\text { Indeks Keseragaman } \\
& H^{\prime} \text { maks = In s ( } \text { s adalah spesies) } \\
& H^{\prime} \text { = Indeks Keaneragaman }
\end{aligned}
$$

Indeks keseragaman berkisar antara 0 -1. Apabila nilai E lebih besar dari 0,6 maka nilai keseragaman tinggi (Kreb, 1978).

Dominasi dengan menggunakan rumus :

$$
\mathrm{C}=\sum[\mathrm{ni} / \mathrm{N}]^{2}
$$

Keterangan $: \mathrm{C}=$ Indeks dominasi;

$\mathrm{Ni} \quad=$ jumlah individu jenis $\mathrm{i}$

$\mathrm{N} \quad=$ Jumlah individu

Nilai D mendekati 1, ada jenis tertentu yang dominan (Odum, 1993) 


\section{Hasil dan Pembahasan}

\section{Jenis dan Kelimpahan Plankton}

Tabel 1. Jenis, kelimpahan dan indeks keanekaragaman ( $\left.\mathrm{H}^{\prime}\right)$, indeks keseragaman ( $\left.\mathrm{E}^{\prime}\right)$ serta indeks dominan (D') plankton pertambakan di Bontang Kuala

\begin{tabular}{|c|c|c|c|c|}
\hline \multirow{2}{*}{ No. } & \multirow{2}{*}{ Jenis Plankton } & \multicolumn{3}{|c|}{ Lokasi Sampling } \\
\hline & & T1 & T2 & T3 \\
\hline \multirow{7}{*}{$\begin{array}{c}\text { A. } \\
1\end{array}$} & Phytoplankton & & & \\
\hline & Crysophyceae & & & \\
\hline & Coscinodiscus sp & 126 & 126 & 126 \\
\hline & Navicula sp & 189 & - & 126 \\
\hline & Nitzschia sp & 189 & 189 & 126 \\
\hline & Pinnularia viridis & 63 & - & - \\
\hline & Pleurosigma sp & 252 & 189 & 63 \\
\hline \multirow{4}{*}{$\begin{array}{c}\text { B. } \\
1\end{array}$} & Zooplankton & & & \\
\hline & Crustaceae & & & \\
\hline & Acartia clausi & 126 & 63 & 126 \\
\hline & Tigriopus japonicus & 189 & 126 & 189 \\
\hline \multicolumn{2}{|c|}{ Jumlah Ind.Plankton/Liter } & 1134 & 693 & 756 \\
\hline \multicolumn{2}{|c|}{ Jumlah Taksa } & 7 & 5 & 6 \\
\hline \multicolumn{2}{|c|}{ Indeks Keanekaragaman (H') } & 1,88 & 1,55 & 1,75 \\
\hline \multicolumn{2}{|c|}{ Indeks Keseragaman (E') } & 0,97 & 0,96 & 0,98 \\
\hline \multicolumn{2}{|c|}{ Indeks Dominan (D') } & 0,16 & 0,22 & 0,18 \\
\hline
\end{tabular}

Keterangan : T1 = Tambak Bontang Kuala in let; T2 = Tambak Bontang Kuala tengah; Tambak Bontang Kuala Out let.

Hasil pengamatan komposisi jenis dan perhitungan kelimpahan, indeks keanekaragaman $\left(\mathrm{H}^{\prime}\right)$, indeks keseragaman (E') serta indeks dominan (D') plankton pada pertambakan di Bontang Kuala disajikan pada Tabel 1. Kondisi perairan pertambakan di Bontang Kuala (lokasi sampling) tergolong miskin plankton. Hal ini terlihat dari hasil pengamatan jenis dan indeks keanekaragaman plankton pada lokasi sampling pertambakan di Bontang yang tidak cukup banyak. Pada pertambakan di Bontang Kuala teridentifikasi hanya 1 kelas fitoplankton, yaitu kelas Crysophyceae (5 spesies); sedangkan zooplankton terdiri dari 1 kelas, yaitu kelas Crustacea (2 spesies) (Gambar 1).

Berdasarkan kelimpahan individu total plankton pertambakan di Bontang Kuala ini pada lokasi sampling T1 berkisar 1134 ind/L; lokasi sampling T2 berkisar 693 ind/L dan lokasi sampling T3 berkisar 756 ind/L. Kelimpahan plankton yang paling tinggi terdapat pada jenis fitoplankton dari kelas Crysophyceae, sedangkan kelimpahan plankton terendah berasal dari kelas Crustacea, yaitu jenis zooplankton.

Jenis plankton yang paling banyak ditemukan berasal dari kelas Crysophyceae (fitoplankton) dengan prosentase jumlah 68\% dan kelimpahan antara $63-252$ ind/L; sedangkan jenis zooplankton pada pertambakan di Bontang teridentifikasi dengan kelimpahan antara 63 - 189 ind/L yang umumnya ditemukan dari kelas Crustacea sebesar $32 \%$ (Gambar 2). 

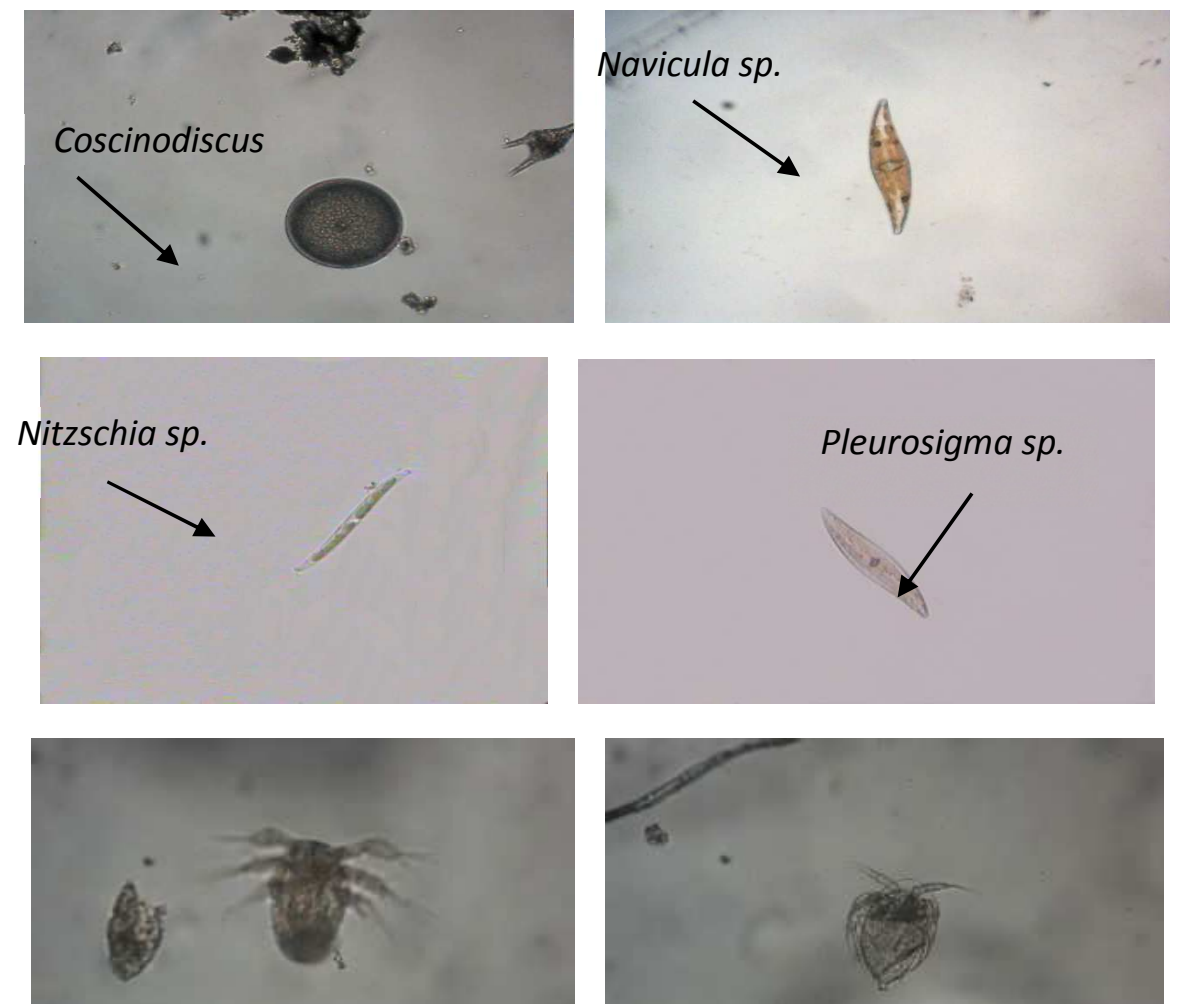

Acartia clause

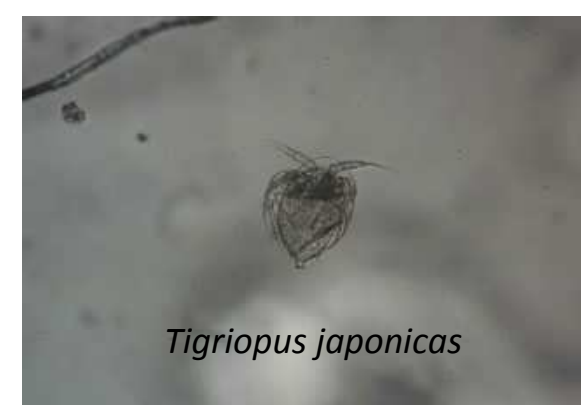

Gambar 1. Jenis-jenis plankton yang banyak ditemukan di pertambakan Bontang $(10 \times 10$ Pembesaran).

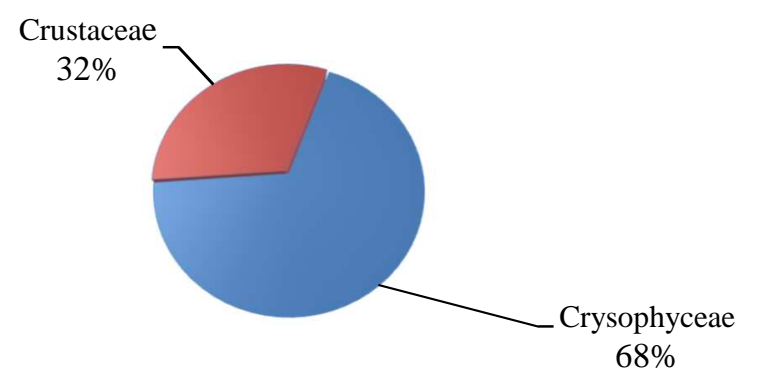

Gambar 2. Proporsi jenis plankton yang teridentifikasi pada pertambakan di Bontang Kuala.

Pada tambak di Bontang, plankton yaitu jenis fitoplankton yang dominan dari kelas Chrysophyceae yang berfungsi sebagai produsen dalam rantai makanan, dan dapat dimanfaatkan oleh zooplankton.

Secara kualitas, fitoplankton yang teridentifikasi pada pertambakan di Bontang ini cukup baik, karena merupakan jenis yang disukai oleh larva ikan/udang dan ikan/udang pemakan plankton. Sedangkan jumlah jenis dan kelimpahan jenis plankton lainnya, yaitu golongan zooplankton relatif lebih sedikit. 
Indeks keanekaragaman plankton yang terdapat pada pertambakan di Bontang berkisar antara 1,55-1,88. Nilai tersebut menunjukkan bahwa keanekaragaman jenis plankton dalam kategori sedang. Nilai keanekaragaman $1<\mathrm{H}^{\prime}<3$; artinya keanekaragaman sedang, penyebaran sedang, kestabilan komunitas sedang. Berdasarkan kriteria dari indeks keanekaragaman ( $\left.H^{\prime}\right)$ (Basmi, 2000), secara umum semua stasiun sampling memiliki keanekaragaman spesies yang tergolong sedang $\left(H^{\prime}: 1-3\right)$ dimana stabilitas komunitas biota termasuk kedalam tingkat moderat, artinya kondisi komunitas di semua lokasi sampling mudah berubah hanya dengan mengalami pengaruh lingkungan yang relatif kecil. Nilai-nilai tersebut menunjukkan bahwa kehidupan antar jenis plankton cukup baik, berimbang, dan tidak ada dominansi. Pagoray et al. (2015), menyatakan bahwa indeks keanekaragaman plankton sangat dipengaruhi oleh kualitas air.

Indeks keseragaman (E') adalah indeks yang menggambarkan keseimbangan spesies yang menyusun komunitas suatu ekosistem. Indeks keseragaman plankton pada masing-masing lokasi sampling yang didapatkan selama periode penelitian ini berlangsung berkisar antara 0,96-0,98; hal ini menunjukkan bahwa komposisi plankton penyusun komunitasnya relatif seimbang, dan tidak ada spesies yang mendominasi struktur komunitas yang ada di perairan tersebut. Artinya pada lokasi sampling tersebut, setiap spesies yang ada mampu beradaptasi dan berkompetisi dalam pemanfaatan unsur hara secara baik dan berimbang. Berdasarkan hasil perhitungan, nilai indeks keseragaman jenis (E) plankton termasuk keseragamannya lebih besar dari 0,6 (Krebs, 1978), yang berarti keseragaman tinggi.

Indeks dominansi selama penelitian berkisar 0.16 - 0.22 . Nilai indeks dominansi yang diperoleh menunjukkan bahwa pada lokasi penelitian tidak terdapat jenis plankton yang dominan. Walaupun ada jenis tertentu yang selalu muncul pada setiap pengamatan namun kelimpahannya tidak menujukkan adanya dominansi. Menurut Odum (1996), jika nilai indeks dominansi semakin mendekati nilai 1, maka menandakan bahwa ada spesies tertentu yang mendominasi pada struktur komunitas plankton di daerah tersebut.

\section{Jenis dan Kelimpahan Benthos}

Berdasarkan hasil pengamatan terhadap kelimpahan dan komposisi benthos pertambakan di Bontang disajikan dalam Tabel 2. Jenis dan kelimpahan benthos pada pertambakan di Bontang tergolong rendah. Pada pertambakan di Bontang teridentifikasi 2 filum benthos dengan kelimpahan yang bervariasi terdiri dari filum Gastrophoda (2 spesies) dan filum Pelecypoda (1 spesies) (Tabel 2), sedangkan Prosentase kehadiran filum Gastrophoda dan Pelecypoda yang teridentifikasi pertambakan di Bontang dapat dilihat pada Gambar 3. 
Tabel 2. Jenis dan kelimpahan benthos di perairan pertambakan Bontang Kuala.

\begin{tabular}{|c|c|c|c|c|}
\hline \multirow{2}{*}{ No. } & \multirow{2}{*}{ Jenis Benthos } & \multicolumn{3}{|c|}{ Lokasi Sampling } \\
\hline & & T1 & T2 & T3 \\
\hline A. & $\begin{array}{l}\text { Gastropoda } \\
\text { Cerithidea pliculosa } \\
\text { Telescopium sp } \\
\text { Pelecypoda } \\
\text { Arca imbricate }\end{array}$ & $\begin{array}{r}1339 \\
-\end{array}$ & $\begin{array}{r}1924 \\
-\end{array}$ & $\begin{array}{r}143 \\
13\end{array}$ \\
\hline \multicolumn{2}{|c|}{ Jumlah Ind.Benthos/m² } & 1339 & 1924 & 169 \\
\hline \multicolumn{2}{|c|}{ Jumlah Taksa } & 1 & 1 & 3 \\
\hline \multicolumn{2}{|c|}{ Indeks Keanekaragaman $\left(\mathrm{H}^{\prime}\right)$} & 0,00 & 0,00 & 0,54 \\
\hline \multicolumn{2}{|c|}{ Indeks Keseragaman ( $\left.E^{\prime}\right)$} & 0,00 & 0,00 & 0,49 \\
\hline \multicolumn{2}{|c|}{ Indeks Dominan (D') } & 1,00 & 1.00 & 0.73 \\
\hline
\end{tabular}

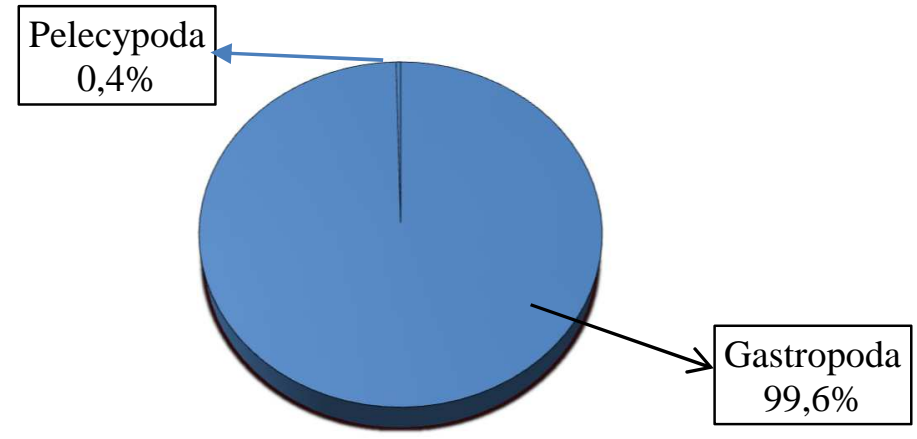

Gambar 3. Prosentase kehadiran filum Gastrophoda dan Pelecypoda yang teridentifikasi pertambakan di Bontang.

Benthos merupakan bermacam jenis hewan yang hidup dan berkembangbiak di dasar perairan (sungai, danau, laut, situ) dan lainnya. Organisme golongan ini biasanya hidup di dasar dengan cara menempel pada batu, membenamkan diri dalam lumpur dan pasir, bergerak dengan mengikuti arus. Kelimpahan dan keanekaragaman benthos sangat baik digunakan sebagai bio-indikator kualitas perairan, karena tingkat kepekaan organisme ini berbeda-beda terhadap jenis bahan pencemar dan memberikan reaksi yang cepat, kemampuan mobilitas yang rendah sehingga secara langsung terpengaruh oleh substansi lingkungan, relatif mudah didapat, diidentifikasi dan dianalisa dibandingkan dengan organisme lain.

Kelimpahan individu total benthos berkisar antara $143 \mathrm{ind} / \mathrm{m}^{2}$ sampai $1924 \mathrm{ind} / \mathrm{m}^{2}$. Jenis benthos yang paling sering ditemukan adalah dari filum Gastrophoda dengan kelimpahan tertinggi $1924 \mathrm{ind} / \mathrm{m}^{2}$, dan spesies yang paling banyak setiap lokasi sampling yaitu Cerithidea pliculosa; sedangkan kelimpahan benthos terendah berasal filum Pelecypoda (13 ind $\left./ \mathrm{m}^{2}\right)$. 
Hasil analisa menunjukkan bahwa tingkat kehadiran dari filum Gastrophoda pada beberapa lokasi sampling mencapai 99,96\%; sedangkan dari filum Pelecypoda 0,04\% (Gambar 3). Kemampuan filum Gastrophoda bertahan hidup di semua lokasi sampling pertambakan ini sangat berkaitan dengan subtrat di dasar perairan yang kebanyakan lumpur dan berpasir serta banyaknya bahan organik.

Berdasarkan hasil perhitungan indeks keanekaragaman $\left(\mathrm{H}^{\prime}\right)$ benthos pada beberapa lokasi pengambilan sampel tergolongan rendah, karena $\left(H^{\prime}<1\right)$ yakni berkisar antara 0,00 sampai dengan 0,54 ; seperti yang disajikan pada Tabel 2. Secara umum, indeks keanekaragaman benthos pada pertambakan tersebut mempunyai stabilitas yang sangat rendah. Hal ini diduga bahwa bahan organik yang ada di dasar perairan dan merupakan sumber makanannya sudah sangat sedikit sehingga tidak mampu lagi mendukung kehidupan organisme benthos tersebut.

Indeks keseragaman (E') benthos di lokasi sampling pertambakan ini berkisar antara 0,00 sampai dengan 0,49 . Kriteria lingkungan yang ada di perairan ini berada dalam kondisi stabil. Menurut Basmi (2000) bahwa nilai indeks keseragaman seperti di atas menunjukkan keseragaman antar spesies penyusun komunitas pada pertambakan tersebut sangat rendah yaitu lebih kecil dari 0,6 (Basmi, 2000), artinya kelimpahan individu yang dimiliki oleh masing-masing spesies sangat jauh berbeda atau bahkan hanya didominasi oleh 1 spesies saja. Hal ini disebabkan karena terjadinya tekanan ekologis di perairan baik bersifat fisika, kimia maupun biologis. Jenis Gastrophoda yang sering ditemukan adalah Cerithidea pliculosa dengan jumlah yang bervariasi. Cerihidea sp merupakan salah satu jenis dari Gastropoda, phylum Moluska. Cerihidea sp dapat digunakan sebagai bioakumulator. Menurut Widiyanti, dkk.,(2005) dalam Rahmad dkk. (2015) bahwa Moluska termasuk yang hidup di daerah estuaria (air payau) dan adanya bahan pencemar di perairan dapat terakumulasi dalam tubuh Moluska.

Hasil perhitungan nilai indeks dominansi (D') dari setiap lokasi sampling pengamatan diperoleh kisaran antara 0,73 - 1,00. Jika diperoleh nilai D mendekati $1(<1,0)$, berarti terdapat jenis yang mendominasi perairan atau nilai indeks dominansi yang diperoleh menunjukkan bahwa sebagian besar pada lokasi penelitian ini terdapat jenis benthos yang dominan. Secara umum lokasi sampling pada pertambakan di Bontang memiliki stabilitas komunitas biota yang sangat rendah. Hal ini mengindikasikan bahwa kondisi lingkungan, khususnya dasar perairan tambak tersebut sudah mengalami perubahan sehingga kurang mampu mendukung kebutuhan jenis benthos untuk hidup dan berkembang biak.

\section{Kesimpulan}

Berdasarkan hasil analisis pada tambak sampling (Bontang Kuala) maka dapat disimpulkan sebagai berikut: 
1. Komposisi plankton yang ditemukan sebanyak 2 kelas, yaitu kelas Crysophyceae dan Crustacea. Kelimpahan plankton pada pertambakan tersebut selama periode penelitian berkisar 693 - 1134 ind/L. Indeks keanekaragaman ( $\left.H^{\prime}\right)$ plankton termasuk dalam kategori komunitas sedang, keseragaman $(E)$ termasuk dalam kategori komunitas stabil dan dominansi (D) tidak ada jenis plankton tertentu yang mendominasi.

2. Jenis dan kelimpahan benthos pada lokasi sampling (pertambakan di Bontang) variasinya sangat rendah, yaitu 2 filum (Gastrophoda dan Pelecypoda) yang terdiri dari 3 spesies dengan kelimpahan 169 - 1924 ind/m². Indeks keanekaragaman (H') benthos termasuk dalam kategori komunitas rendah; sedangkan indeks dominansi (D) benthos pada pertambakan ini lebih cenderung pada kondisi ada mendominasi jenis benthos tertentu.

\section{Daftar Pustaka}

Basmi, J. (2000). Planktonologi: Plankton sebagai Bioindikator Kualitas Perairan. Fakultas Perikanan dan IImu Kelautan, Institut Pertanian Bogor.

Davis, G.C. (1955). The Marine and Freshwater Plankton, Michigan State University Press. USA. 526 p.

Hutabarat, S. Dan S.M. Evans. (1995). Pengantar Oseanografi. Universitas Indonesia Press.

Kendeigh S. Charles. (1980). Ecologi with Special Reference to Animals and Man. Prentice-Hal of india, New Delhi.

Krebs, C. J. (1978). Ecology. The Experimental Analysis of Distribution and Abudance. Harper \& Row Publ.: New York.

Musa, M. (2004). Kondisi Kualitas Air Pada Budidaya Campuran Ikan Bandeng dan Udang di Tambak Garam Sumenep Madura. Jurnal Penelitian Perikanan 7(1), ISSN 0854 $-3685$.

Newell, G.E. and R.C. Newell, 1963. Marine Plankton a Practical Guide. Hutchinson Educational Ltd 178 -202 Great Portland Street, London W-1.

Nybakken, J.W. (1988). Biologi Laut, Suatu Pendekatan Ekologis. Penerbit Gramedia: Jakarta.

Odum, E. P. (1993). Dasar-Dasar Ekologi. Alih Bahasa: Samingan, T. Gadjah Mada University Press: Yogyakarta.

Pagoray H., Ghitarina, Deni Udayana, (2015). Kualitas Plankton Pada Kolam Pasca Tambang Batubara yang Dimanfaatkan Untuk Budidaya Perairan. Majalah IImiah Pertanian Ziraa'ah. 40(2): 108 - 113.

Rahmad A.W.,Tarzan P., Reni A. 2015. Kadar Timbal (Pb) dan Kepadatan Pupulasi Cerihtidea sp di Pantai Selatan Kabupaten Bangkalan Madura, Jawa Timur. LanteraBio ISSN 2252 - 3979. Vol 4 No.3. p:174 -179.

Yamaji, C.S. 1979. Illustration of The Marine Plankton of Japan. Hoikusha Publishing Co., Ltd Japan. 572 p. 